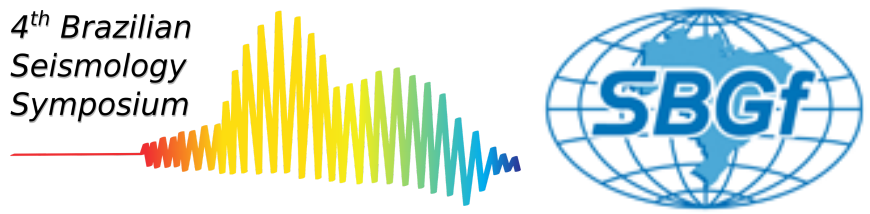

\title{
Shear wave splitting studies in Amazon Craton
}

\author{
Leonardo Almeida de Sá, George Sand França, Giuliano Sant'Anna Marotta. \\ Seismological Observatory - Institute of Geosciences - University of Brasilia \\ Copyright 2021, SBGf - Sociedade Brasileira de Geofísica. \\ This paper was prepared for presentation during the $17^{\text {th }}$ International Congress of the Brazilian Geophysical Society held in Rio de Janeiro, Brazil, 8-11 November 2021 (Online Event). \\ Contents of this paper were reviewed by the Technical Committee of the $17^{\text {th }}$ International Congress of the Brazilian Geophysical Society and do not necessarily represent any position of \\ the SBGf, its officers or members. Electronic reproduction or storage of any part of this paper for commercial purposes without the written consent of the Brazilian Geophysical Society is \\ prohibited.
}

Seismic birefringence is a phenomenon that occurs due to the interaction of the shear wave with a rocky body, allowing information on the lithosphere anisotropy. The shear wave splitting studies, when compared with other geophysical methods, provide answers regarding tectonic processes that are present during the evolution, this includes the observation and analysis of the flow of the upper mantle, in addition to checking if there is a possible correlation with the geological trends present in the region. Also, these studies are extremely important to have information regarding the deformation of the upper mantle referring to different geological processes. In this study, the main objective is to obtain anisotropy guidance in the upper mantle. The study was carried out using data provided by the Seismological Observatory. Events that had magnitudes above 5.6 Mw were taken into account for the study, along with a distance window ranging from $90^{\circ}$ to $130^{\circ}$ for the analysis of the SKS and SKKS wave phases. In this work, we present new measurements of shear wave splitting in Amazon Craton.

The preliminary results obtained from the delay time and fast polarization for each station and the results are from $1.55-2.5 \mathrm{~s}$ for delay time and from $40-67^{\circ}$ for fast polarization. The fast polarization orientations have an average NE-SW trend and are consistent with the mantle flow around the Amazon Craton. 